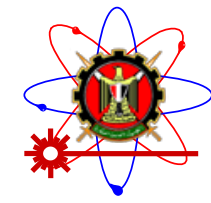

\title{
PH-5
}

\section{Role of chromo-photometry of the vehicle interior lighting in modern automotive ergonomy}

M. Nazeeh Tawfeek Ali, W.M. Hussein, H.S.Ayoub and Yehya Hendawy

\begin{abstract}
:
This work discusses the effect of the intensity colored lighting used in the car interior and its probable effect on the driver's eye performance, considering its relation with partial eye glance time. Also a proposed method to apply chromophotometry to evaluate and enhance car lighting design on ergonomic bases
\end{abstract}

\section{Keyword:}

Car interior lighting, colored light, eye response time, eye glance time, car chromophotometry, interior lighting design, ergonomy.

\section{introduction:}

Modern automotive industry has yield an new branch of applied engineering termed in-car design, a science that studies the design of car interior on ergonomic bases. Many literatures now are treating this subject in order to increase the safety and comfort of the driver, specially after the retreat of mechanical differences between cars, produced by most of automotive company around the world. A new problem arises when one attempts to evaluate and differentiates between two or more car of the same class or of a similar engine performance. Almost no standard evaluation method is described in this concern till the time of writing this manuscript. This work integrates many physical and technical parameters in one evaluation test, using a relatively simple procedure that eases the 
Military Technical College

Kobry Elkobbah,

Cairo, Egypt

April 19-21,2016

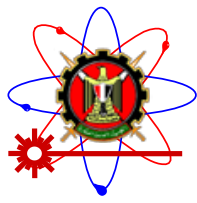

$8^{\text {th }}$ International Conference on Mathematics and Engineering Physics (ICMEP-8)

selection of the suitable car, in favor of safety and comfort of the driver and the user.

\section{Previous evaluation attempts}

Most important method used in evaluating Toyota [1] cars, relaying on what so called Ergo-index and situational suitability index

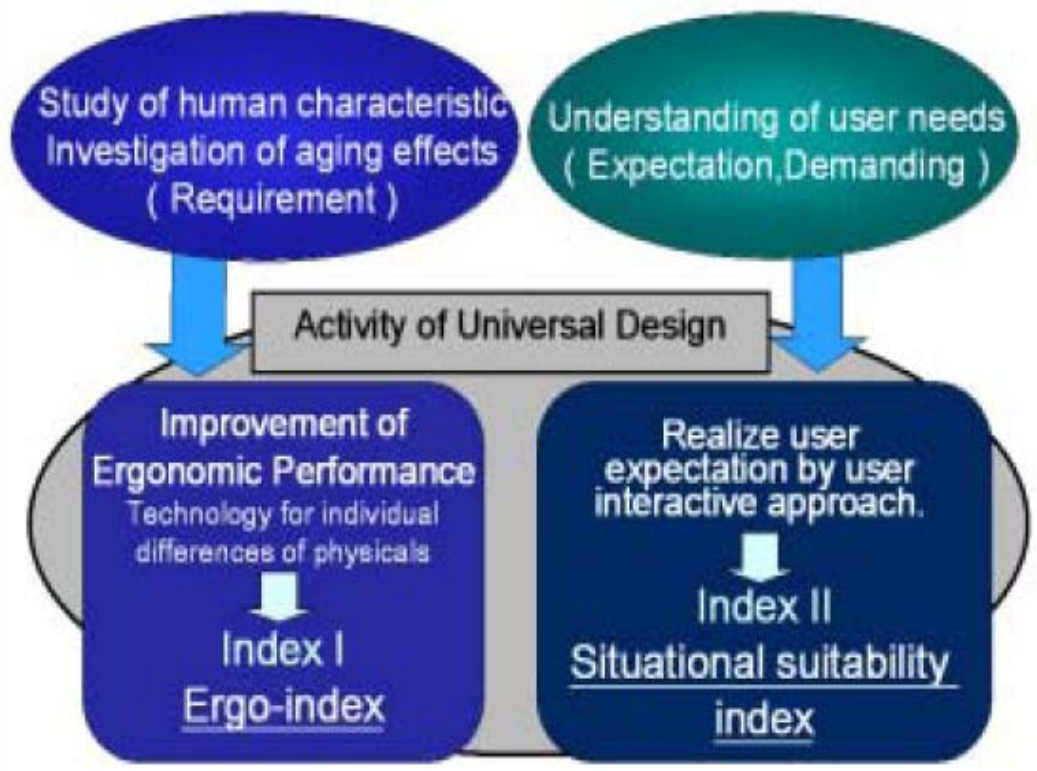

Figure 1 Toyota evaluation method

This evaluation method is very limited on the Toyota ergonomic standards to meet its marketing demands and does not take into account several issues to be discussed shortly in this work. 
Military Technical College

Kobry Elkobbah,

Cairo, Egypt

April 19-21,2016

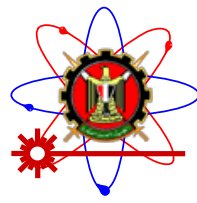

$8^{\text {th }}$ International Conference on Mathematics and Engineering Physics (ICMEP-8)

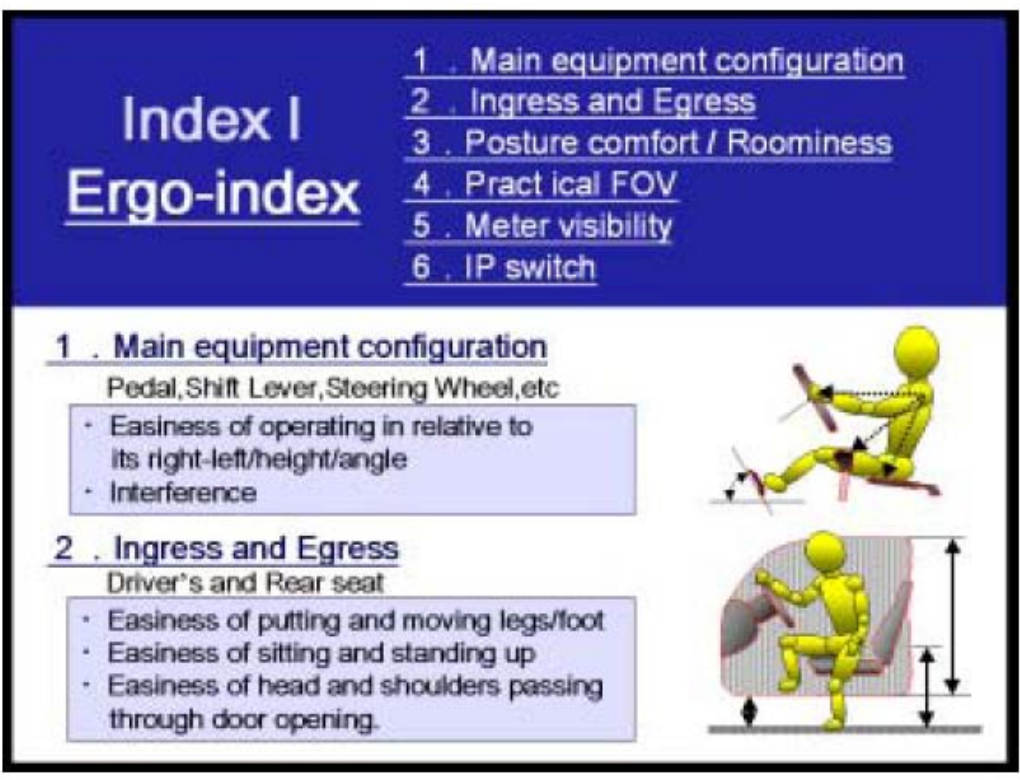

A: Example of evaluation items

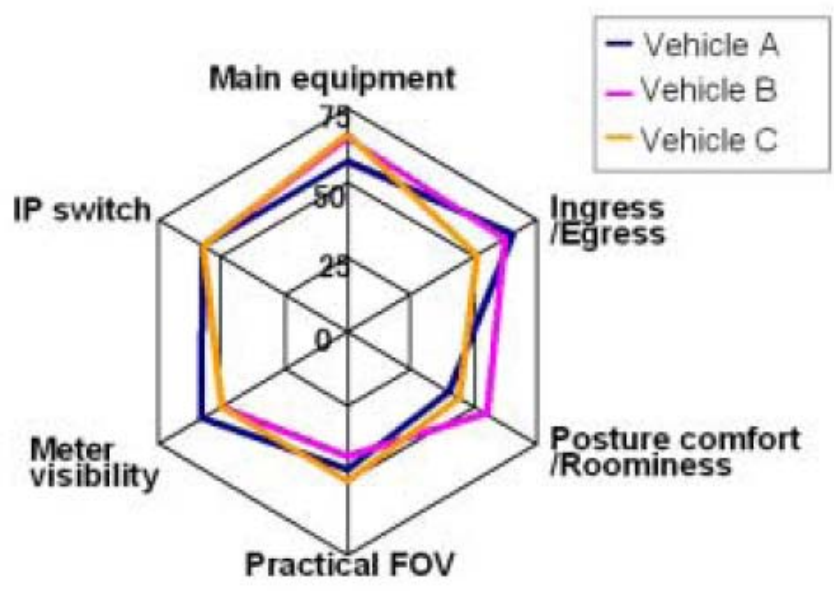

Figure 2 Toyota definition of ergo-index

\section{Factors Affecting the Evaluation Process}

One can select the suitable car according to three bases namely ergonomic, economic and technical factors. These factors are composing the evaluations criteria, that enable the examiner to favorite one design over another. Each Factor comprise many elements as shown in figure 3 


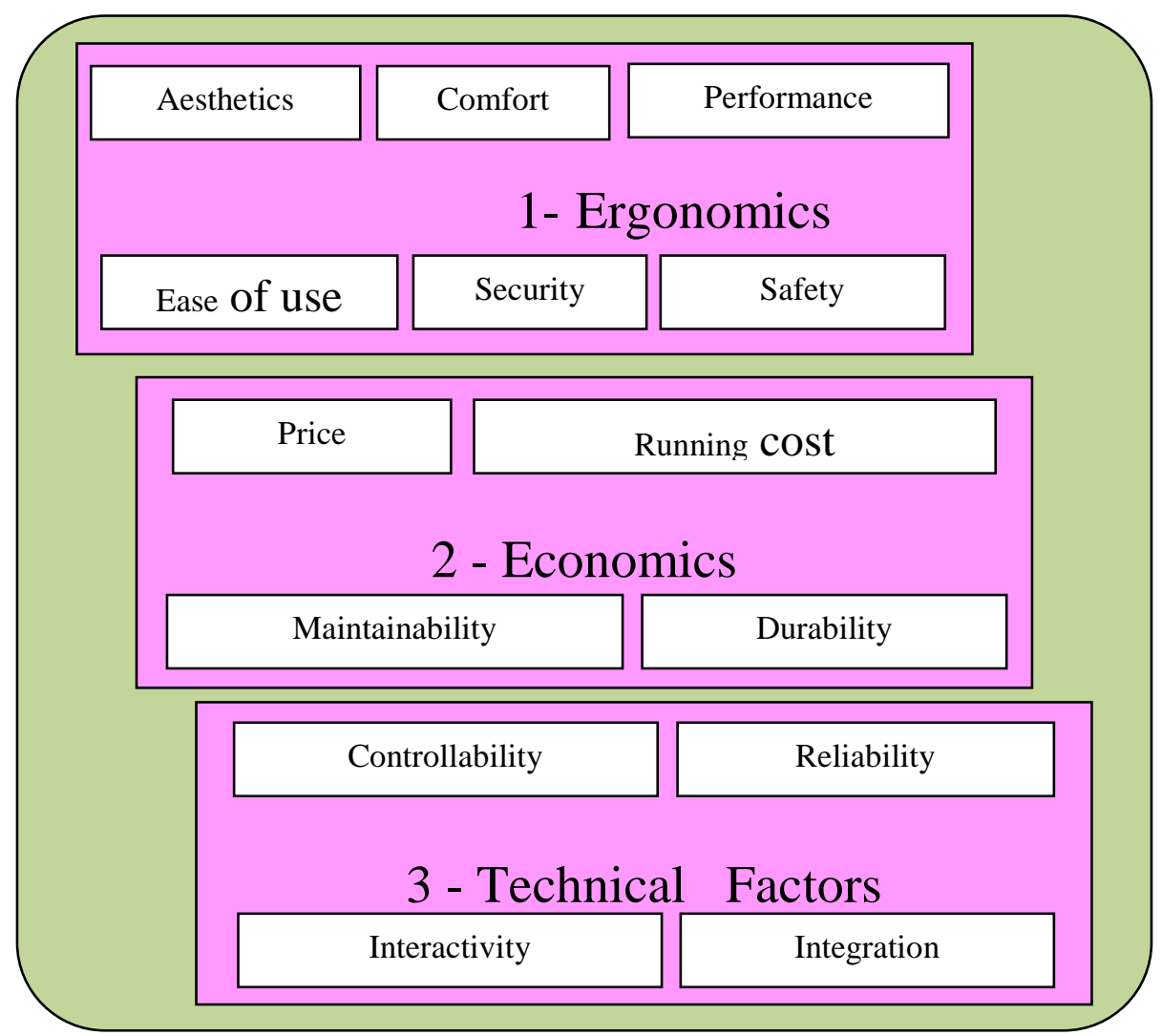

Figure 3 the basic factors affecting in-car evaluation

The previous three bulk factors (weight factors) are the framework of a novel modeling simply termed three weight (TW) model. The advantage of such model is that it integrates between many separated conceptions usually treated as independent approaches of in-car evaluation that was basically concerned in pure ergonomic point of view. According to international Ergonomics Association (IEA), ergonomics can be broadly classified into/under three definitions:

i. Physical Ergonomics which is concerned with human anatomical, anthropometric, physiological and biomechanical characteristics as they related to physical activity. Relevant topics may include working postures, material handling, repetitive movements, work related 


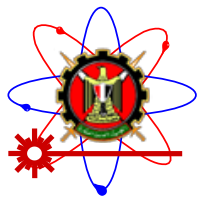

musculoskeletal disorders, workplace layout, health and safety.

ii. Cognitive Ergonomics: A proper fit of a product to a user does not end with physical interfaces. Cognitive / perceptual ergonomics is concerned with mental processes, such as perception, memory, reasoning, and motor response, as they affect interactions among humans and other elements of a system. Relevant topics include mental workload, decisionmaking, skilled performance, human-computer interaction, human reliability, work stress and training as these may relate to human-system and Human computer interaction design.

iii. Organizational Ergonomics: It is concerned with the optimization of socio technical systems, including their organizational structures, policies, and processes. Relevant topics include communication, crew resource management, work design, design of working times, teamwork, community ergonomics, cooperative work, new work programs, virtual organizations, telework, and quality. management.

a major contribution is made in this work when the authors decided to include security for the first time under the definition of cognitive ergonomics, the thing that was missing before this model. Security is a major and crucial human concern that could lead to a total discomfort. We can understand security by many means:

i. The security of the driver in his car against physical and visual abuse. 
Military Technical College

Kobry Elkobbah,

Cairo, Egypt

April 19-21,2016

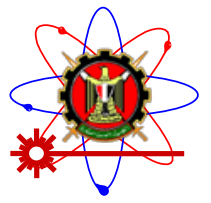

$8^{\text {th }}$ International Conference on Mathematics and Engineering Physics (ICMEP-8)

ii. The security of the driver's property, privacy and information.

iii. The security of the car and its immunity against total or partial theft trials.

\section{Car Class according to TW model}

Vehicles can be categorized according to the car's construction, engine, weight, type of fuel and emissions, as well as the purpose for which it is used.

Another standard for road vehicles of all types that is used internationally, is ISO 3833-1977. Many private enterprise and car rental companies use the ACRISS Car Classification Code to describe the size, type and equipment of vehicles to ensure that rental agents can match customer needs to available vehicles, the Insurance Institute for Highway Safety uses a scheme it has developed that takes into account a combination of both vehicle size and other vehicle features such as length and wheelbase. The United States National Highway Traffic Safety Administration (NHTSA) separates vehicles into classes by the curb weight of the vehicle with standard equipment including the maximum capacity of fuel, oil, coolant, and air conditioning, if so equipped. The United States Federal Highway Administration has developed a classification scheme used for automatically calculating road use tolls. The United States Environmental Protection Agency (US EPA) has developed a classification scheme used to compare fuel economy among similar vehicles. A similar set of classes is used by the Canadian EPA. The Canadian National Collision Database (NCDB) system defines "passenger car" as a unique class, but also identifies two other categories 
Military Technical College

Kobry Elkobbah,

Cairo, Egypt

April 19-21,2016

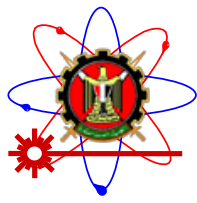

$8^{\text {th }}$ International Conference on

Mathematics and Engineering

Physics (ICMEP-8)

involving passenger vehicles the "passenger van" and "light utility vehicle"

Table 1 some examples of current car classification systems

\begin{tabular}{|c|c|}
\hline $\begin{array}{l}\text { Highway Loss Data Institute } \\
\text { classification }\end{array}$ & Definition \\
\hline Sports & Cars with significant high performance feature \\
\hline Luxury & Higher-end cars that are not classified as sport \\
\hline Large & $\begin{array}{l}\text { Length more than } 495.3 \mathrm{~cm} \text { (195 in) and whe } \\
279.4 \mathrm{~cm}(110 \mathrm{in})\end{array}$ \\
\hline Midsize & $\begin{array}{l}\text { Length } 457.3 \text { to } 495.3 \mathrm{~cm}(180-195 \mathrm{in}) \text { and } \\
279.4 \mathrm{~cm}(105-110 \mathrm{in})\end{array}$ \\
\hline Small & $\begin{array}{l}\text { Length less than } 457.2 \mathrm{~cm} \text { (180 in) and wheell } \\
266.7 \mathrm{~cm}(105 \mathrm{in})\end{array}$ \\
\hline NHTSA classification & Curb weight \\
\hline Passenger cars: mini & 1,500 to $1,999 \mathrm{lb}(680-907 \mathrm{~kg})$ \\
\hline Passenger cars: light & 2,000 to $2,499 \mathrm{lb}(907-1,134 \mathrm{~kg})$ \\
\hline Passenger cars: compact & 2,500 to $2,999 \mathrm{lb}(1,134-1,360 \mathrm{~kg})$ \\
\hline Passenger cars: medium & 3,000 to $3,499 \mathrm{lb}(1,361-1,587 \mathrm{~kg})$ \\
\hline Passenger cars: heavy & 3,500 lb (1,588 kg) and over \\
\hline Sport utility vehicles & - \\
\hline Pickup trucks & - \\
\hline Vans & - \\
\hline EPA car class & Total passenger and cargo volume (cu. ft.) \\
\hline Two-seaters & Any (designed to seat onloryhy two adults) \\
\hline Minicompact & Less than $85 \mathrm{cu} \mathrm{ft}(2,407 \mathrm{l})$ \\
\hline Subcompact & 85 to $99 \mathrm{cu} f t(2,407-2,803 \mathrm{l})$ \\
\hline Compact & 100 to $109 \mathrm{cu} \mathrm{ft}(2,832-3,087 \mathrm{l})$ \\
\hline Mid-size & 110 to $119 \mathrm{cu} \mathrm{ft}(3,115-3,370 \mathrm{l})$ \\
\hline Large & $120 \mathrm{cu} \mathrm{ft}(3,398 \mathrm{l})$ or more \\
\hline Small station wagons & Less than $130 \mathrm{cu} \mathrm{ft}(3,681 \mathrm{l})$ \\
\hline Mid-size station wagons & 130 to $159 \mathrm{cu} \mathrm{ft}(3,681-4,502 \mathrm{l})$ \\
\hline Large station wagons & $160 \mathrm{cu} \mathrm{ft}(4,531 \mathrm{l})$ or more \\
\hline
\end{tabular}

as shown in figure 4, the intersection of the main sets of factors of TW model can yield a new car class taxonomy that can be used to select the basic questions of the evaluation test. 


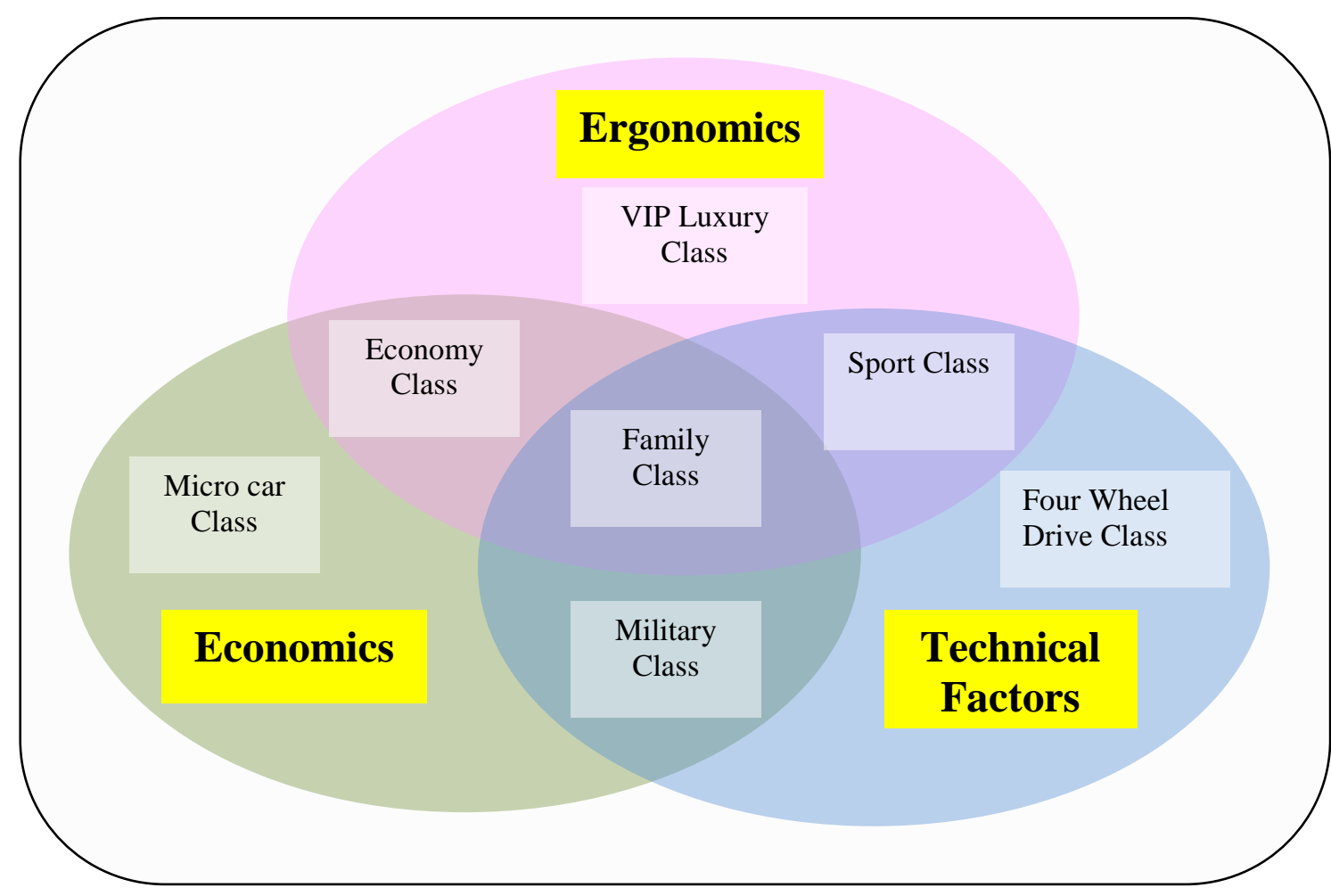

Figure 4 New car class taxonomy based on TW model

\section{Theory and Structure of the test}

Let us consider an imaginary perfect $\operatorname{car} x$ in the space of certain TW class, with $n$ in-car characteristic option and another real imperfect car $y$ from the same space, with $\mathrm{m}$ in-car characteristic option such that $n>m$ then:

$$
I_{T W}=m / n \quad I_{T W}<1
$$

Where $I_{T W}$ is defined as the three weight index describing how far is the in-car design of car $y$ from being perfect relative to car $x$.

$\mathrm{n}$ and $\mathrm{m}$ can be distinguished into three assembly pairs $n_{\text {Ergonomic }}$, $m_{\text {Ergonomic }}, n_{\text {Economic }}, m_{\text {Economic }}$ and $n_{\text {Technical }}, m_{\text {Technical }}$ or:

$$
I_{N T W}=A\left(m_{\text {Ergonomid }} / n_{\text {Ergonomic }}\right)+B\left(m_{\text {Economid }} / n_{\text {Economic }}\right)+C\left(m_{\text {Technical }} / m_{\text {Technical }}\right)
$$


Where $I_{N T W}$ is the normalized three weight index, $A, B$ and $C$ are the weighting coefficients such that:

$$
A+B+C=1
$$

It should be noticed that these coefficients must be positive numbers ranging from zero to less that one. The weight of each coefficient is selected according to the priority of the assembly in the TW class.Table 2 shows an example of proposed weighting for each class test.

Table 2 weighting coefficients vs car class

\begin{tabular}{|c|c|c|}
\hline TW car class & \multicolumn{2}{|c|}{ weighting coefficients ( $A$, } \\
\hline Micro cars & $A=0.3$ & $\mathrm{~B}=0.6 \mathrm{C}=0.1$ \\
\hline Economic cars & $\mathrm{A}=0.4$ & $B=0.4 \quad C=0.2$ \\
\hline Family cars & $A=0.5$ & $\mathrm{~B}=0.3 \mathrm{C}=0.3$ \\
\hline VIP luxury cars & $A=0.8$ & $\mathrm{~B}=0.1 \quad \mathrm{C}=0.1$ \\
\hline Sport cars & $A=0.7$ & $B=0.1 \quad C=0.2$ \\
\hline Four Wheel Drive cars & $A=0.3$ & $\mathrm{~B}=0.3 \mathrm{C}=0.4$ \\
\hline Military cars & $\mathrm{A}=0.2$ & $B=0.4 \quad C=0.5$ \\
\hline
\end{tabular}

It is worth to mention that this test is flexible enough as an upgradeable test to include any number of features or options in context of daily advances in modern automotive interior design by simply changing $n$.

\section{Measuring the Non Specified Data}

The vision is a crucial factor in the driving task as most of the information received by the driver come through the visual sense $[4,5]$. The clear view of road (front and rear) enables the driver a safe driving. Poor visibility conditions are stressful for the drivers and results in a significantly increased risk of accident, The view ahead through the wind shield has to be sufficient and clear for the driver. It enables driver to stop 


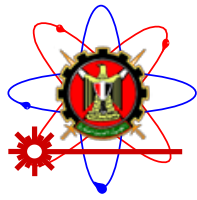

in emergency and necessary conditions. Similarly, rear and side views are important for maintaining speed, taking turn, exerting break or during parking. On the road driver need much longer view to anticipate and prepare for avoiding actions. Views close to the vehicle is equally important when turning left or right in order to maintain proper distance to avoid accidents, therefore the test must include question about the field of view FOV. Unfortunately FOV can not be obtained from the operation manual of the car, but it has to be measured for each car under evaluation and each element of the FOV must have its own evaluation question in the test. (For example the rear and Lateral FOV, the minimum eye and neck movement ..ect).

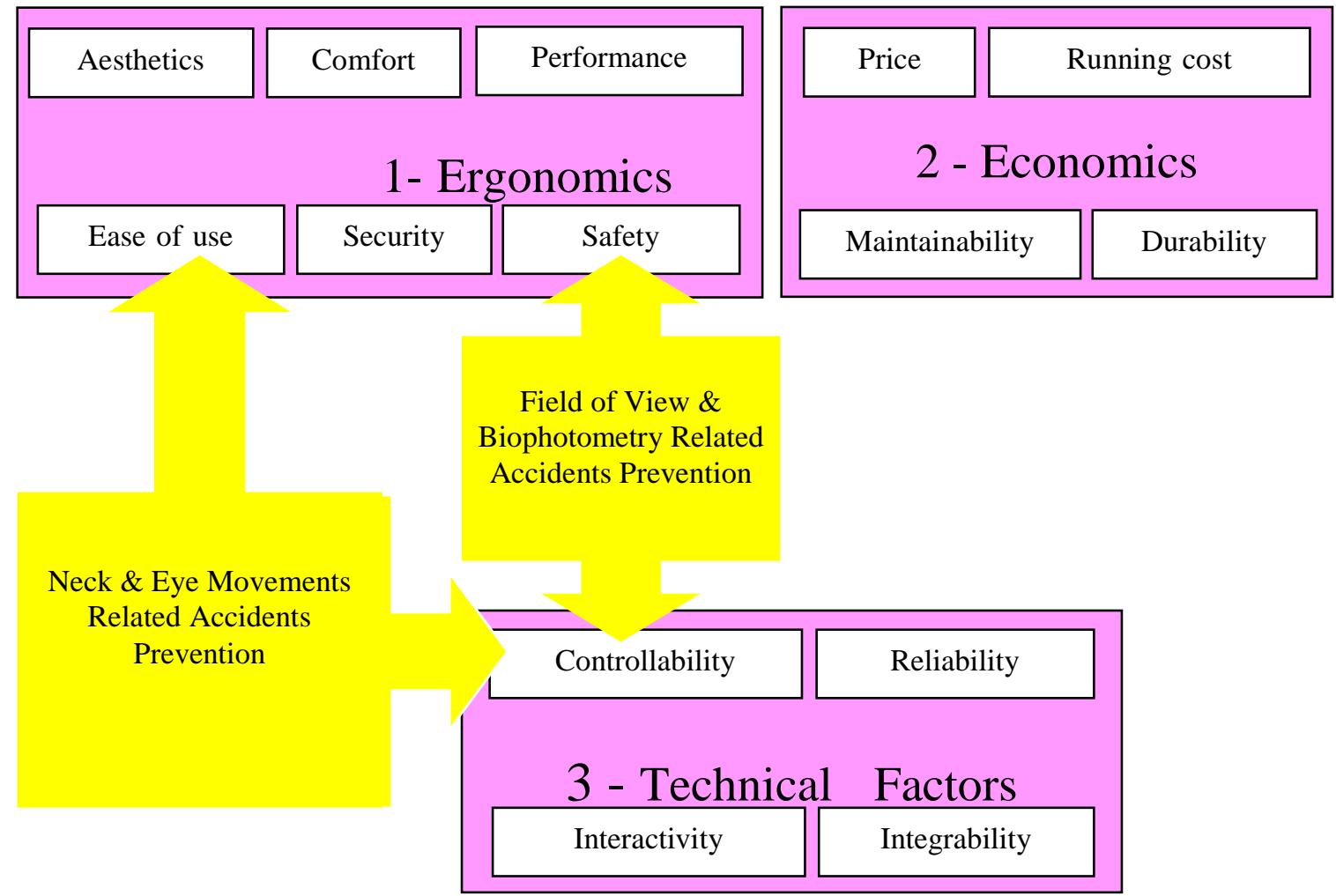

Figure 5 the essential measurement needed to tolerate the NTW index test and their position in the TW model 
Military Technical College

Kobry Elkobbah,

Cairo, Egypt

April 19-21,2016

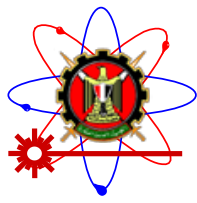

$8^{\text {th }}$ International Conference on Mathematics and Engineering Physics (ICMEP-8)

\section{Conclusion}

The TW model is a simple approach that could be used easily to summarize most of the human demands when selecting a car based on its interior design, and to differentiate between cars of the same classes obtained from the mentioned model. An new concept was used to enhance the definition of ergonomy by adding security as subsidiary. The theory of in-car evaluation upgradeable test through NTW index was deduced, including the prediction of the weighting coefficients. The importance of measuring the FOV was also mentioned.

\section{Acknowledgment}

The authors are greatly thankful to all committee of the Egyptian technical military college for their helpful support and suggestion.

\section{References}

1- Kenji Misugi, Hitoshi Kanamori, Bunji Atsumi, Toyota's Program for Universal Design in Vehicle Development - Universal Design for The Toyota "RAUM"Toyota Motor Corporation 1, TOYOTA-CHO, TOYOTA-SITY, AICHI 471-8572, JAPAN.(2000)

2- Vivek_D_Bhise,_Ergonomics_in_the_automotive_design, CRC Press ISBN 9781-4398-4211-9 (2012)

3- International Ergonomics Association. What is Ergonomics. Official webpage.

4- International Organization for Standardization, "ISO 3833:1977 Road vehicles - Types - Terms and definitions", (2014).

5- Insurance Institute for Highway Safety, Highway Loss Data Institute (HLDI), Technical Appendix, Arlington, Virginia. (2000)

6- Clayton, Alan; Montufar, Jeannette; Middleton, Dan; McCauley, Bill "Feasibility of a New Vehicle Classification System for Canada" , U.S. Department of Transportation. (August 2000).

7- Australian FCAI VFACTS, Motor Vehicle Classifications and Definitions". Federal Chamber of Automotive Industries (1999).

8- L. M.Forbes, Field of View from Automotive Vehicles, Ford Motor Company., Report SP-381. Presented at the Automobile Engineering Meeting, Detroit, MI. Warrendale. (1973). 